\title{
Antibacterial Effect of Diode Laser in Pulpectomy of Primary Teeth
}

\author{
Zahra Bahrololoomi $^{1}$, Reza Fekrazad ${ }^{2}$, Shiva Zamaninejad ${ }^{3 *}$ \\ 'Pediatric Dentistry, Faculty of Dentistry, Shahid Sadughi University of Medical Sciences, Yazd, Iran \\ ${ }^{2}$ Research Center in Medical Sciences, AJA University of Medical Sciences, Tehran, Iran \\ ${ }^{3}$ Pediatric Dentistry, Faculty of Dentistry, Golestan University of Medical Sciences, Gorgan, Iran
}

\section{*Correspondence to \\ Shiva Zamaninejad, Assistant \\ Professor of Pediatric Dentistry, \\ Faculty of Dentistry, Golestan \\ University of Medical Science, \\ Gorgan, Iran. \\ Tel: +98 9113718638; \\ Email: sh.zamani66@gmail.com}

Published online 27 September 2017

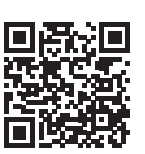

\begin{abstract}
Introduction: Laser irradiation has been suggested as an adjunct to traditional methods of canal preparation but few studies are available on the antibacterial effect of diode laser in pulpectomy of primary teeth. The purpose of the present study is to investigate the antibacterial effect of diode laser in pulpectomy of primary teeth, in addition to define the optimal and harmless diode lasing conditions in the root canal.

Methods: A total of 125 single rooted primary teeth were selected. After traditional canal cleaning, they were divided in 2 groups. Sixty-five specimens after culturing of Enterococcus faecalis into the canals, were divided in 3 groups: (1) traditional canal cleaning with $0.5 \%$ $\mathrm{NaOCl}$ irrigation, (2) method of group $1+1.5 \mathrm{~W}$ diode laser (980 nm, pulse), (3) without treatment ( 5 specimens). Then the specimens were cultured and after colony counting under light microscope, were statistically analyzed by Kruskal-Wallis and Mann-Whitney tests. For 60 specimens, temperature rise of apical and cervical parts of the external root surface were measured using 2 thermocouple type $\mathrm{K}$, when radiating a $1.5 \mathrm{~W}$ diode laser into the canal. Results: In the first experiment, the diode laser group showed tmost reduction in bacterial count. And in the second experiment, the mean temperature rise of external root surface was less than the threshold of periodontal ligament (PDL) damage.

Conclusion: Diode laser with a power output of $1.5 \mathrm{~W}$, is effective in reduction of $E$. faecalis bacterial count without damaging periodontal structures.

Keywords: Diode laser; Pulpectomy; Primary teeth.
\end{abstract}

\section{Introduction}

It is not wise to maintain the infected primary teeth without treatment. These teeth are a source of infection and should be treated or extracted. Pulpectomy of primary teeth is a conservative method of treatment versus extraction. Preserving natural tooth is important because of space maintenance, chewing ability and appearance. ${ }^{1,2}$ Nowadays the most common method of root treatment of necrotic primary teeth is complete pulpectomy that needs a perfect accessibility to the root canals. Root morphology of primary teeth makes endodontic treatment hard and often impossible. ${ }^{3}$ Recent studies have shown that present root treatment techniques should be changed or improved to avoid failure of endodontic treatment. ${ }^{1}$ Bacteria exist throughout the root canal such as isthmuses, and dentinal tubules. Enterococci are a cause of endodontic infections. From this group, Enterococcus faecalis is common. E. faecalis is a main cause of failures in endodontic treatment. Although more present in infected permanent teeth, $E$. faecalis is abundant in primary teeth too. The positive results of endodontic treatment will increase significantly if the infection is controlled correctly. ${ }^{4}$ Bactericidal effects of different types of lasers like Er-YAG, Nd-YAG and diode lasers has been proved in endodontic treatment of permanent teeth. ${ }^{5,6}$ In addition, the properties of laser light provide a bactericidal effect that penetrates more than $1 \mathrm{~mm}$ through dentinal thickness. Nowadays diode laser has been concerned because it is economic, has a good bactericidal effect and its temperature rise has been shown to be in an acceptable range for permanent teeth. ${ }^{6}$ One of the important observations when using laser as an adjunctive modality for endodontic treatments is the heat that the laser produces may damage periodontal structures around the tooth. ${ }^{6,7}$ The thickness of dentine and enamel is lower in primary teeth than in permanent teeth, so laser may cause the external root temperature to rise higher than permanent teeth. The aim of this study was in vitro assessment of the bactericidal effect of diode laser in pulpectomy of primary teeth and also to verify the external root temperature rise when diode laser is used into the root canals of primary teeth.

\section{Methods}

A total of 120 freshly extracted, single rooted, anterior 
primary teeth with a single canal were used and prepared as following; first the roots were cut to a length of approximately $10 \mathrm{~mm}$ by a diamond bur on a high speed handpiece and were stored in a $0.05 \% \mathrm{NaOCl}$ solution. Two experiments were prepared in this study.

1. To measure the external root temperature rise during laser irradiation into the canal, 60 prepared teeth were used and root canals were prepared up to an apical size No. 60 (Dental K-File, Japan, Mani) and were irrigated by $10 \mathrm{~mL} 0.5 \% \mathrm{NaOCl}$ and then by normal saline solution.

After that the canals were dried with paper point number 40, 50, 60. A $980 \mathrm{~nm}$ diode laser (laser ARC, FOX Germany) was used. The fiber tip was $600 \mu \mathrm{m}$ in diameter. To prevent the effect of hand temperature, a cylindrical acrylic mold that was $5 \mathrm{~cm}$ in height and diameter was used to hold the tooth during laser radiation. A hole was prepared in the center of the mold's circle to fix the tooth and a hole in the height of the mold with a connection to the upper hole to put the probe of thermocouple in contact with apical region of the tooth. As there was no available study with this goal, a series of pilots have been done on 50 teeth according to Table 1, to obtain the greatest power output of laser that does not increase the temperature of external root surface more than $7^{\circ} \mathrm{C}$ (threshold of periodontal ligament [PDL] injuries).

According to Table 1, the power output of $1.5 \mathrm{~W}$ was used for this study. A thermo conductor paste (Wärmeleitpaste WPN 10, Germany) was spread on the root surface to ensure as maximum thermal contact as possible between the tip of thermocouple probe and the root surface. Each tooth was fixed inside the acrylic mold, two type $\mathrm{K}$ thermocouples (Autonics, Korea) with a $1 \mathrm{~mm}$ diameter probe were used to measure the apical and cervical temperatures of the root synchronously. The measurement accuracy was $0.1^{\circ} \mathrm{C}$. The probe of one thermocouple was fixed in the groove of the acrylic mold

Table 1. Pilot Examinations to Reach Appropriate Irradiation Time of Diode Laser $980 \mathrm{~nm}$

\begin{tabular}{lcc}
\hline No. of Teeth & Radiation Time (s) & $\begin{array}{c}\text { No. of Teeth With } \\
\text { More Than } 7^{\circ} \mathbf{C} \text { Rise }\end{array}$ \\
\hline 10 & $30(\mathrm{CW})$ & 10 \\
10 & $10(\mathrm{CW})$ & 5 \\
10 & $5-5^{*}-5$ (pulse) & 2 \\
10 & $5-10^{*}-5-10^{*}-5$ (pulse) & 2 \\
10 & $5-10^{*}-5$ (pulse) & 0 \\
\hline
\end{tabular}

Abbreviation: CW, continuous wavelength.

* Resting time. at the cervical region of the root. Then the probe of second thermocouple was entered from the hole existing in the height of the cylinder and was placed in close contact with the apical region of the root. Then the working length was measured by a K-file for each tooth and the measuring size was marked on the fiber tip of the laser by a silicone stop. A $980 \mathrm{~nm}$ diode laser (Laser ARC, FOX Germany) with the power output of $1.5 \mathrm{~W}$, irradiated pulsatory with the pulse length of $30 \mathrm{~ms}$ and the speed of $2 \mathrm{~mm} / \mathrm{s}$. The fiber tip was entered into the canal to reach $1 \mathrm{~mm}$ upper than working length, and the laser was radiated in pulse mode and rotation. The whole time intra canal lasted 20 seconds, lasing for 2 times of 5 seconds each (radiation time), one resting time of 10 seconds (interval). To compare the temperature changes at the root surface with the temperature changes of the room another thermocouple with the same features was placed at room. Temperatures were recorded every second in a period of 20 seconds. And the difference between the room temperature with the apical and cervical temperatures was calculated. Then data were assessed statistically by SPSS 17 .

2. Sixty prepared teeth were used to evaluate the antibacterial effect of diode laser. Root canals were prepared up to an apical size No. 60 and were irrigated by normal saline and then by $0.5 \% \mathrm{NaOCl}$. Then the canals were dried by paper point number $40,50,60$. A small piece of light cure Glass Ionomer (GC Fuji, Japan) was cured at the apical foramen of each tooth to obstruct the apical opening. Then the roots were sterilized in an autoclave at $134^{\circ} \mathrm{C}$ for 15 minutes. A suspension of E. faecalis (ATCC 29212) strand was incubated in $5 \mathrm{~mL}$ trypticase soy broth (TSB) culture medium at $37^{\circ} \mathrm{C}$ in incubator for 24 hours. Then the concentration of inoculation was adjusted to reach a degree of turbidity according to McFarland scale which specifies a bacterial concentration of $1.5 \times 10^{8}$ cells $/ \mathrm{mL}$, and specifying an absorbance of 0.08 to 0.1 at wavelength of $600 \mathrm{~nm}$. Each root canal was filled with $0.1 \mathrm{~mL}$ of suspension with an insulin syringe. Then teeth were set up vertically inside the trypticase soy agar (TSA) plates. Four thick TSA plates were used to support the teeth vertically, and 16 teeth were fixed in each plate. Plates were incubated at $37^{\circ} \mathrm{C}$ inside a laboratory incubator. After 48 hours, the specimens were removed from the incubator and were divided into 2 groups of 30 roots. One group of 30 roots was prepared with the common method of pulpectomy. As each tooth was prepared with the files No. 30 to 60 and after each filing, was irrigated with normal saline solution. At the end step

Table 2. Temperature Rise During Irradiation of Diode Laser With 1.5 W Power of, $2 \times 5$ Seconds Pulse With 10 Seconds Interval

\begin{tabular}{|c|c|c|c|c|}
\hline & Number & Minimum & Maximum & Mean \pm SD \\
\hline Temperature of room & 60 & 29.60 & 32.60 & $31.48 \pm 0.67$ \\
\hline Temperature of cervical region & 60 & 31.60 & 34.20 & $32.94 \pm 0.67$ \\
\hline Temperature of apical region & 60 & 33.90 & 39.30 & $37.45 \pm 1.06$ \\
\hline Difference between room temperature and cervical temperature & 60 & 0.30 & 4.20 & $1.45 \pm 0.70$ \\
\hline Difference between room temperature and apical temperature & 60 & 3.70 & 7.10 & $5.97 \pm 0.69$ \\
\hline
\end{tabular}


the roots were irrigated with $0.5 \% \mathrm{NaOCl}$ solution. A separate series of sterile $\mathrm{k}$-files were used for each tooth to minimize the transmission of bacteria from one tooth to another. In addition all steps were accomplished under laboratory fume hood to observe the sterility.

Each tooth was carried just with a sterile forcep, after completing pulpectomy steps and irrigation with $0.5 \%$ $\mathrm{NaOCl}$ solution, sampling was achieved from within the canal with a paper point No. 50 entered into the canal up to the working length and kept in for 5 minutes and then transferred immediately into an experimental tube size $100 \times 12 \mathrm{~mm}$ including $5 \mathrm{~mL}$ TSB sterile solution and a tube cap was set.

The other group of 30 roots was prepared with the aforesaid pulpectomy method and after irrigating with $0.5 \% \mathrm{NaOCl}$ solution, a $980 \mathrm{~nm}$ diode laser (Laser ARC, FOX, Germany) with $1.5 \mathrm{~W}$ power output was irradiated in pulse mode into the root canal for 20 seconds (two 5 seconds irradiation time and one interval of 10 seconds). Then sampling was immediately achieved with a paper point No. 50 in a rotational movement and transferred to a separate experimental tube including $5 \mathrm{~mL}$ TSB solution. Separate series of sterile k-files were used for each tooth in this group too. The fiber tip of laser was disinfected after each irradiation into each root canal by a piece of cotton soaked in Deconex (Deconex Solarsept) disinfection solution. After that, all experimental tube including one specimen were transferred to the Vortex machine and vibrated for 30 seconds. Then microscope slides of specimens were prepared and colony counts were assessed with a light microscope. Data were transferred to SPSS 17 and Kruskal-Wallis and Mann-Whitney tests were used for statistical analysis

\section{Results}

In the first experiment, from 60 specimens, after an irradiation time of 20 seconds, temperature did not rise more than the threshold at the cervical region, but at the apical region temperature increased more than the threshold in 2 specimens that it was $7.1^{\circ} \mathrm{C}$ for each one. As it is shown in Table 2, the mean temperature difference between the apical region and room was lower than the threshold.

In the second experiment, there were 2 groups of 30 roots. As it is shown in Table 3, for the first group that the treatment was common pulpectomy without using laser, the mean of colony counts of bacterial growth was 37.9 but for the second group that the treatment was common pulpectomy adding diode laser, the mean colony counts was 2.7. As a result of both Mann-Whitney tests the difference was significant $(P<0.006)$.

\section{Discussion}

The goal of this study was to find a suitable power output of diode laser that does not damage PDL tissue. The result of this study showed that irradiation of diode laser with a power output of $1.5 \mathrm{~W}$ and pulse duration of 20
Table 3. Bacterial Colony Count in the Study Groups

\begin{tabular}{lcc}
\hline Group & No. of Teeth & $\begin{array}{c}\text { Mean Colony } \\
\text { Count }(\log 10) \pm \text { SD }\end{array}$ \\
\hline Pulpectomy without laser & 30 & $37.9 \pm 1.61$ \\
Pulpectomy with laser & 30 & $2.7 \pm 1.94$ \\
Without treatment (control) & 5 & $140.0 \pm 0.99$ \\
\hline
\end{tabular}

seconds (lasing 2 times of 5 seconds each, and an interval of 10 seconds) does not damage periodontal tissues. The threshold of PDL injuries has been demonstrated in the literature to be $7^{\circ} \mathrm{C} .^{7-9}$ Many types of lasers have been studied to characterize their bactericidal effect in permanent teeth. The first one was $\mathrm{CO} 2$ laser. But it was shown that $\mathrm{CO} 2$ laser is not suitable for endodontic procedures because of its high temperature rise. ${ }^{10}$ Diode laser has been used in many studies as an adjunctive treatment of endodontics. And it has shown a high level of bactericidal effect. ${ }^{5,11,12}$ Different power outputs of diode laser has been used in literature. In a study, external root temperature rise of apical region was evaluated for a $635 \mathrm{~nm}$ diode laser with a power output of $100 \mathrm{~mW}$, used for 150 seconds on permanent teeth. The results showed that all temperature rises were below the safety level of $7^{\circ} \mathrm{C} .{ }^{4}$ Whereas our study was on primary teeth and an important aspect of children's treatment is to get as minimal time as possible, and in order to render our study valuable clinically, we decided to choose a superior power output but lower irradiation of time. In a study, $810 \mathrm{~nm}$ diode laser with a $4 \mathrm{~W}$ power output, 5 seconds, was used to reduce intra canal bacteria. The results showed that this laser was effective for eliminating E. faecalis. ${ }^{13}$ The 810 $\mathrm{nm}$ diode laser has also been used in another study with a power output of $3 \mathrm{~W}$ in continuous mode (CW) for 30 seconds and $74 \%$ reduction of $E$. faecalis was observed for a dentinal thickness of 500 microns. ${ }^{14}$ Also, in the study of Schoop et al, a $810 \mathrm{~nm}$ Diode laser at 1 and $1.5 \mathrm{~W}$ power was used. The results showed a high disinfection capability for both power outputs but significantly higher with 1.5 W. Also as another result of this study, more power output showed more bactericidal effect. ${ }^{6}$ In the other hand, as there was no available study with this goal in primary teeth and because of less thickness of dentin and enamel in primary teeth we decided to find the highest power output of diode laser that does not rise the temperature of external root surface more than $7^{\circ} \mathrm{C}$. So according to other studies, we decided to choose a power output of at least $1.5 \mathrm{~W}$ to be valuable for the main goal of bactericidal effect. And then find an appropriate irradiation time to solve the problem of temperature rise.

The study of Dickers et al. showed that the amount of temperature rise on the root surface is correlated to the duration of laser irradiation. ${ }^{4}$ So while radiating intra canal with such lasers the fiber should be motioned throughout the whole track, with a rotational movement. ${ }^{4,15}$

The reason for our results showing no significant temperature rise (no more than $7^{\circ} \mathrm{C}$ ), may be this rotational technique that we used in whole track in and out 
of the root canal. As it is known, the highest temperature rises occur in the apical region of the root. ${ }^{4}$ In our study the same result occurred as it is shown in Table 2. Our study was on primary teeth, the apical part of the root is not as important as it is in permanent teeth for treatment failures. Because the most pathologic radiolucencies and the most accessory canals, that are the main reason of relapse if they are not cleaned well, are in the furcation region in primary teeth. And hand instrumentation often cannot clear these accessory canals completely. Thus, the laser could be more radiated in the cervical region and less in the apical part of the root to reduce the temperature rises. But this is just a comment and needs more studies to find the best type of laser irradiation in primary teeth to provide the best clinical criteria.

In the study of Kuvvetli et al performed on primary teeth, canal irrigation by $5.25 \% \mathrm{NaOCl}$ solution showed more antibacterial effect than both diode and Er:YAG lasers. ${ }^{6}$ This result was different from the results of this study and it may be because of different power output and lasing time and more importantly because of $\mathrm{NaOCl}$ concentration, that was $0.5 \%$ in this study compared to $5.25 \%$ in the Kuvvetli et al study, where the bactericidal effect of $\mathrm{NaOCl}$ was higher.

\section{Ethical Considerations}

The research protocol was approved by the Ethical Committee of Yazd Medical University Sciences (protocol $\neq \mathrm{P} / 17 / 1 / 31861$ ).

\section{Conflict of Interests}

The authors declare no conflict of interest.

\section{References}

1. Moskovitz M, Sammara E, Holan G. Success rate of root canal treatment in primary molars. J Dent. 2005;33(1):4147. doi:10.1016/j.jdent.2004.07.009

2. Ramar K, Mungara J. Clinical and radiographic evaluation of pulpectomies using three root canal filling materials: an in-vivo study. J Indian Soc Pedod Prev Dent. 2010;28(1):2529. doi:10.4103/0970-4388.60481

3. Dean JA, Avery DR, McDonald RE. McDonald and Avery's dentistry for the child and adolescent. In: McDonald RE, Avery DR, Dean JA, eds. Treatment of deep caries, vital pulp exposure and pulpless teeth. 9th ed. St Louis, Mo: Mosby
Elsevier Inc; 2011: 2011:354.

4. Dickers B, Lamard L, Peremans A, et al. Temperature rise during photo-activated disinfection of root canals. Lasers Med Sci. 2009;24(1):81-85. doi:10.1007/s10103-007-0526-y

5. Kuvvetli SS, Sandalli N, Topcuoglu N, Kulekci G. Antibacterial efficacy of diode and Er:YAG laser irradiation in experimentally contaminated primary molar root canals. J Clin Pediatr Dent. 2009;34(1):43-48.

6. Schoop U, Kluger W, Moritz A, Nedjelik N, Georgopoulos A, Sperr W. Bactericidal effect of different laser systems in the deep layers of dentin. Lasers Surg Med. 2004;35(2):111116. doi:10.1002/lsm.20026

7. Nammour S, Kowaly K, Powell GL, Van Reck J, Rocca JP. External temperature during KTP-Nd:YAG laser irradiation in root canals: an in vitro study. Lasers Med Sci. 2004;19(1):27-32. doi:10.1007/s10103-004-0303-0

8. Machida T, Wilder-Smith P, Arrastia AM, Liaw LH, Berns MW. Root canal preparation using the second harmonic KTP:YAG laser: a thermographic and scanning electron microscopic study. J Endod. 1995;21(2):88-91. doi:10.1016/ s0099-2399(06)81102-7

9. Sauk JJ, Norris K, Foster R, Moehring J, Somerman MJ. Expression of heat stress proteins by human periodontal ligament cells. J Oral Pathol. 1988;17(9-10):496-499.

10. Anic I, Dzubur A, Vidovic D, Tudja M. Temperature and surface changes of dentine and cementum induced by $\mathrm{CO} 2$ laser exposure. Int Endod J. 1993;26(5):284-293.

11. Preethee T, Kandaswamy D, Arathi G, Hannah R. Bactericidal effect of the $908 \mathrm{~nm}$ diode laser on Enterococcus faecalis in infected root canals. J Conserv Dent. 2012;15(1):46-50. doi:10.4103/0972-0707.92606

12. Asnaashari M, Safavi N. Disinfection of Contaminated Canals by Different Laser Wavelengths, while Performing Root Canal Therapy. J Lasers Med Sci. 2013;4(1):8-16.

13. Moritz A, Gutknecht N, Goharkhay K, Schoop U, Wernisch J, Sperr W. In vitro irradiation of infected root canals with a diode laser: results of microbiologic, infrared spectrometric, and stain penetration examinations. Quintessence Int. 1997;28(3):205-209.

14. Gutknecht N, van Gogswaardt D, Conrads G, Apel C, Schubert C, Lampert F. Diode laser radiation and its bactericidal effect in root canal wall dentin. J Clin Laser Med Surg. 2000;18(2):57-60. doi:10.1089/clm.2000.18.57

15. Gutknecht N, Franzen R, Meister J, Vanweersch L, Mir M. Temperature evolution on human teeth root surface after diode laser assisted endodontic treatment. Lasers Med Sci. 2005;20(2):99-103. doi:10.1007/s10103-005-0347-9 